\title{
Trace metals in soil, dust, and tree leaves of the urban environment, Guangzhou, China
}

\author{
BI XiangYang ${ }^{1,2}$, LIANG SiYuan ${ }^{1} \&$ LI XiangDong ${ }^{1 *}$ \\ ${ }^{1}$ Department of Civil and Environmental Engineering, The Hong Kong Polytechnic University, Hung Hom, Kowloon, Hong Kong, China; \\ ${ }^{2}$ State Key Laboratory of Biogeology and Environmental Geology, China University of Geosciences (Wuhan), Wuhan 430074, China
}

Received March 12, 2012; accepted April 23, 2012; published online September 16, 2012

\begin{abstract}
Metals have been constantly introduced to urban environments via various point and non-point sources of pollution, and have contaminated different urban compartments (sample types). However, most research projects have focused on a single environmental compartment to characterize urban metal contamination. In the present study, an integrated sampling program that includes surface soils, different size fractions of soil and road dust $(<50 \mu \mathrm{m}, 50-100 \mu \mathrm{m}, 100-250 \mu \mathrm{m}$, and 250-1000 $\mu \mathrm{m})$, tree leaves, and grasses, was conducted in a typical urban area of Guangzhou, China. The aim of the study was to investigate the interrelationships among the metal pollutants in these samples. The concentrations of trace metals varied greatly among different sample types, and their distribution was generally in the following order: road dust $>$ soil dust $\geqslant$ surface soils $\approx$ top soils $>$ grasses $\geqslant$ tree leaves. As for the relationships among the trace metals, different combinations were seen among the sample types, indicating different loadings of trace metals in the sampling medium. Significant correlations of metal concentrations were found between tree leaves and the smallest $(<50 \mu \mathrm{m})$ fraction of road dust, and between soil dust $(50-100 \mu \mathrm{m})$ and surface soils, suggesting that trace metals in these samples may influence each other.
\end{abstract}

urban environment, trace metals, soil, dust, tree leaf, grass

Citation: Bi X Y, Liang S Y, Li X D. Trace metals in soil, dust, and tree leaves of the urban environment, Guangzhou, China. Chin Sci Bull, 2013, 58: 222-230, doi: $10.1007 / \mathrm{s} 11434-012-5398-2$

Increasingly, urban environments, especially those in developing countries, are being degraded due to intensified anthropogenic activities, posing a potential health threat to more than half of the global population, who live in urban areas. Trace metal contamination is an important factor in this degradation. Ajmone-Marsan and Biasioli [1] reviewed current literature on trace metal pollution in the urban soils of about 94 world cities. Their results revealed that most cities are contaminated by one or more types of metals. Similarly, Luo et al. [2] examined trace metal contamination in urban soils from 21 cities of China, and found that the mean or median concentrations of trace metals in urban soils were significantly higher than the corresponding background soil values. Furthermore, trace metal concentrations were usually high in old industrial cities, where metals

*Corresponding author (email: cexdli@polyu.edu.hk) had been deposited from the emissions of vehicles, power plants, and industrial processes [2].

Soil and dust are important sinks of trace metal contaminants in urban environments. Toxic metals loaded in dust and loose parts of surface soil may have adverse effects on the health of humans, especially children, from the involuntary or direct ingestion of soil particles via the "hand to mouth" pathway. For example, many studies have pointed to a significant correlation between the blood lead levels (BLLs) of children and $\mathrm{Pb}$ concentration in urban soil/dust [3-5]. Furthermore, re-suspended soil or road dust is likely to contribute significantly to fine particulate matter $(<10 \mu \mathrm{m}$, $\mathrm{PM}_{10}$ ) in air, a topic that has been widely studied in relation with the respiratory health of humans [6-8]. Therefore, the trace metals present in soil/dust might have a considerable influence on the composition of $\mathrm{PM}_{10}$ in the surrounding air environment [9]. The potential adverse health effects of 
trace metals may be different between road dust and urban soils due to the different metal loadings and chemical forms associated with them. In addition, road dust and urban soils can influence each other in close urban settings. However, many previous studies have focused on either road dust or urban soil alone, and have not fully investigated the relationship between the two or the influence of metal loadings. Similarly, the differences in trace metal concentrations between the loose parts of soil (soil dust) and among different layers of soil (e.g., 0-3 or 0-15 cm) in an urban environment have not been well studied. In fact, the uppermost layers of soil may affect the oral ingestion or re-suspension of fine soil particles in urban sites.

In addition to soil and dust, biological materials, such as fungi, lichens, grasses, tree bark, and the leaves of higher plants, have also been widely used to detect the deposition, accumulation, and distribution of metal pollution [10-12]. In comparison with soils, which can record anthropogenic inputs of metals for a period of several decades to several hundreds of years, biomaterial samples can only reveal a relatively short time-period of atmospheric metal deposition. Therefore, the combined use of these sample types may provide more precise and detailed information for assessing urban metal contamination and its possible effects on health. Furthermore, an understanding of the distribution of trace metals among these different urban components may facilitate the choice of appropriate and effective methods to investigate anthropogenic impacts on a given urban environment.

Guangzhou (GZ), the capital of Guangdong Province and the urban center of the Pearl River Delta (PRD) region, is one of China's largest industrial centers and as well as one of the most rapidly expanding cities in the country. In the last three decades, its rapid economic development has brought great prosperity to the region, but has also resulted in a wide range of environmental problems [13]. The aim of the present study is to study the rapid environmental changes in Guangzhou, using a combined sampling medium, including soil, soil dust, road dust, grasses, and tree leaves. The major objectives of the present research are as follows: (1) to study trace metal loadings in a typical urban environment; (2) to evaluate the relationship of trace metal distribution patterns among different urban components; and (3) to identify possible sources of trace metals in a typical urban environment.

\section{Materials and methods}

\subsection{Study area and sample collection}

Guangzhou City is located in southeast China $\left(22^{\circ} 26^{\prime}-\right.$ $\left.23^{\circ} 56^{\prime} \mathrm{N}, 112^{\circ} 57^{\prime}-114^{\circ} 03^{\prime} \mathrm{E}\right)$. Its climate is typical of subtropical humid monsoon regions, with an average temperature of $21.2-23.1^{\circ} \mathrm{C}$ and average annual rainfall of $1411-$ $1942 \mathrm{~mm}$ [14]. At the end of 2009, the population numbered 1516 million in ten urban districts within an area of

\section{$3843 \mathrm{~km}^{2}$ [14].}

The study area is located in the western part of the city, and consists of typical industrial, commercial, and residential districts. A total of 22 sampling sites were selected in this area (Figure 1). Generally, only the uppermost layers of urban soils (e.g., 0-3 cm) can be re-suspended, and thereby affect inhalation and oral ingestion. But the degree of mixing in urban soils is very high; therefore, soils sampled at depths of 10 or $15 \mathrm{~cm}$ are often used for assessments of health and ecological risk [15]. The soil samples in this study were collected at two different depths of $0-3 \mathrm{~cm}$ (surface soil) and 0-15 cm (top soil), respectively. Each of the soil samples consisted of 9 sub-samples obtained in a $2 \mathrm{~m} \times$ $2 \mathrm{~m}$ grid using a stainless steel hand auger. Soil dust samples were collected within the same area where the soils had been collected, and road dust samples were collected at the roadside near the soil sampling site. Both soil and road dust samples were collected using a vacuum cleaner equipped with stacked filters. The dust samples were then divided into four size fractions in situ: $<50 \mu \mathrm{m}, 50-100 \mu \mathrm{m}$, $100-250 \mu \mathrm{m}$, and 250-1000 $\mu \mathrm{m}$. For the leaf and grass samples, these were collected from banyan trees (Ficus microcarpa) and manila grass (Zoysia matrella) respectively, as these are found throughout Guangzhou. Grass samples were collected only from the soil sampling sites. During sampling, the green parts of the sward were cut at about 2 $\mathrm{cm}$ above soil level with a stainless-steel knife. Tree leaves were collected from heights of 1.5 to $2 \mathrm{~m}$, in order to achieve representative plant samples. Samples were taken from at least five trees in each sampling site. All of the samples were placed in polyethylene bags for transport and storage.

\subsection{Sample preparation and analysis}

The soil samples were dried in an oven at $60^{\circ} \mathrm{C}$ for $3 \mathrm{~d}$. They then were crashed and sieved through a $1 \mathrm{~mm}$ polyethylene sieve to remove stones, coarse materials, and other debris. Soil/road dust were freeze-dried at $-50^{\circ} \mathrm{C}$, because these samples will undergo further examination to determine if organic pollutants (such as polycyclic aromatic hydrocarbons PAH) are present. The dried soil $(\sim 20 \mathrm{~g})$ and

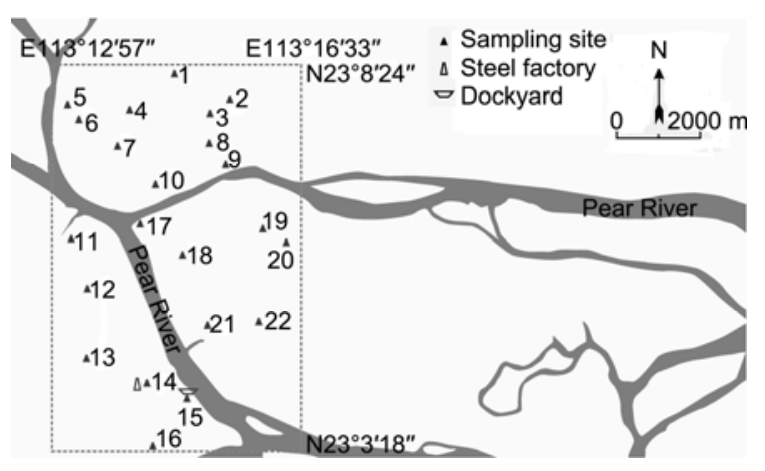

Figure 1 The study area and the sampling locations. 
coarse dust $(>100 \mu \mathrm{m})$ samples were ground in an agate grinder until fine particles $(<200 \mu \mathrm{m})$ were obtained. Each of the plant samples was divided into two parts: washed (by tap water and deionized water) and unwashed. Both the washed and unwashed plant samples were dried in an oven at $60^{\circ} \mathrm{C}$ for $3 \mathrm{~d}$, and then ground into powder with a stainless steel coffee grinder. The prepared samples were then stored in polyethylene bags in a dessicator for further chemical analysis.

The ground soil $(0.25 \mathrm{~g})$, dust $(0.10-0.20 \mathrm{~g})$, and plant samples $(1.0 \mathrm{~g})$ were digested with concentrated $\mathrm{HNO}_{3}$ and $\mathrm{HClO}_{4}(4: 1)$ in an aluminum heating block [16,17]. The total concentrations of major elements $(\mathrm{Ca}, \mathrm{Mg}, \mathrm{Fe}$, and $\mathrm{Al}$ ) and trace metals $(\mathrm{Co}, \mathrm{Cu}, \mathrm{Cr}, \mathrm{Mn}, \mathrm{Ni}, \mathrm{Pb}$, and $\mathrm{Zn}$ ) were determined by inductively coupled plasma-atomic emission spectrometry (ICP-AES, Perkin Elmer Optima 3300DV). Soil $\mathrm{pH}\left(\mathrm{H}_{2} \mathrm{O}\right)$ was determined in a soil to deionized water suspension of $1: 2.5(\mathrm{w} / \mathrm{v})$. For quality control, reagent blanks, replicates, and standard reference materials (SRM 2709 for soil, SRM 1648 for dust, and SRM 1515 and 1573 a for plants), representing $10 \%, 20 \%$, and $10 \%$ of the total sample population, respectively, were incorporated in the analysis to detect contamination and to assess the precision and bias of the analytical program. The recovery rates for most elements in the standard reference materials were around $78 \%-120 \%$, but only $42 \%-63 \%$ for $\mathrm{Al}$ due to the absence of HF in the digestion process.

\subsection{Statistical analysis}

The data were statistically analyzed using the statistical package SPSS v13.0 (SPSS Inc.). A one-way ANOVA test $(P<0.05)$ was used to analyze the variance in metal concen- trations among different sampling sites. Paired-sample $t$-tests were employed to examine the differences in mean metal concentrations between different sample compartments. The correlation analysis was conducted using a Pearson correlation, and the level of significance was set at $P<0.05$ and $P<0.01$ (two-tailed).

\section{Results and discussion}

\subsection{Metal concentrations}

(1) Soils. The concentrations of trace metals $(\mathrm{Co}, \mathrm{Cr}, \mathrm{Cu}$, $\mathrm{Ni}, \mathrm{Pb}$, and $\mathrm{Zn}$ ), as well as $\mathrm{pH}$ value, in surface and top soils are listed in Table 1 . There were no significant differences $(P>0.05)$ in these chemical properties between surface soils $(0-3 \mathrm{~cm})$ and top soils $(0-15 \mathrm{~cm})$, with the exception of $\mathrm{Cr}$ and $\mathrm{pH}(P<0.05)$, indicating the generally uniform distribution of trace metals within the top soil layer of $0-15 \mathrm{~cm}$. However, a few sites showed metal concentrations in surface soils that were notably higher than those in the top soils. For example, the concentrations of $\mathrm{Cu}, \mathrm{Pb}$, and $\mathrm{Zn}$ in the surface soil of Site 20 exceeded their corresponding concentrations in the top soils by 11, 3, and 6 times, respectively, indicating a site-specific source of pollution. The common enrichment of $\mathrm{Cr}$ in surface soils might suggest an enhanced input of $\mathrm{Cr}$ from non-point sources in recent years. The significantly lower $\mathrm{pH}$ of surface soils than top soils was probably due to the common occurrence of acid rain in the PRD region [18]. The highest concentrations of $\mathrm{Cr}$ (287 $\mathrm{mg} / \mathrm{kg})$ and $\mathrm{Zn}(787 \mathrm{mg} / \mathrm{kg})$ were generally found in an industrial region (Site 14, near the GZ steel factory). However, the highest concentrations of $\mathrm{Cu}(246 \mathrm{mg} / \mathrm{kg})$ and $\mathrm{Pb}(195$ $\mathrm{mg} / \mathrm{kg}$ ), and the second-highest concentration of $\mathrm{Zn} \mathrm{(471}$

Table 1 Summary of metal concentrations and $\mathrm{pH}$ of surface soils and top soils from Guangzhou and other Chinese cities

\begin{tabular}{|c|c|c|c|c|c|c|c|c|}
\hline & & $\mathrm{Co}$ & $\mathrm{Cr}$ & $\mathrm{Cu}$ & $\mathrm{Ni}$ & $\mathrm{Pb}$ & $\mathrm{Zn}$ & $\mathrm{pH}$ \\
\hline \multirow{3}{*}{$\begin{array}{l}\text { Surface soils } \\
(n=22)\end{array}$} & Mean \pm SD & $7.01 \pm 1.86$ & $58.1 \pm 56.1$ & $57.6 \pm 44.7$ & $20.6 \pm 6.6$ & $70.3 \pm 47.3$ & $196 \pm 162$ & $7.24 \pm 0.77$ \\
\hline & Median & 7.02 & 42.2 & 45.6 & 19.4 & 55.2 & 148 & 7.45 \\
\hline & Range & $3.21-10.7$ & $21.1-287$ & $15.3-193$ & $11.7-44.8$ & $21.7-179$ & $54.4-787$ & $5.12-8.23$ \\
\hline \multirow{2}{*}{$\begin{array}{l}\text { Top soils } \\
(n=22)\end{array}$} & Mean \pm SD & $6.28 \pm 1.58$ & $39.1 \pm 22.4$ & $47.3 \pm 50.3$ & $18.5 \pm 3.70$ & $67.9 \pm 55.2$ & $155 \pm 122$ & $7.60 \pm 0.85$ \\
\hline & Median & 6.48 & 34.1 & 40.0 & 18.6 & 42.7 & 117 & 7.79 \\
\hline \multicolumn{9}{|l|}{ Guangzhou } \\
\hline \multicolumn{2}{|c|}{ Urban soil (2007) [19] } & & & 62.6 & 25.7 & 109 & 169 & \\
\hline \multicolumn{2}{|c|}{ Urban soil (2001) [20] } & & 87.7 & 24.3 & 17.3 & 63.9 & 121 & \\
\hline \multicolumn{2}{|c|}{ Suburban soil [20] } & & 16.1 & 2.3 & 26.3 & 55.1 & 108 & \\
\hline \multicolumn{2}{|c|}{ Background soil [21] } & 6.3 & 39 & 10.4 & 12.3 & 41 & 58 & \\
\hline \multicolumn{2}{|c|}{ PRD natural soil [22] } & 7.12 & 51.8 & 16.5 & 16.5 & 29.9 & 50.7 & \\
\hline \multicolumn{2}{|l|}{ Beijing [23] } & & 60.3 & 34.4 & 25.9 & 39.5 & 89.6 & \\
\hline \multicolumn{2}{|l|}{ Xiamen [25] } & $4.1(3.7)^{\mathrm{a})}$ & $14(13)$ & $26(18)$ & $8.4(6.7)$ & $36(25)$ & $100(95)$ & \\
\hline \multicolumn{2}{|l|}{ Yibin [26] } & & & $56.4(51.6)$ & & $61.2(46.8)$ & $139(112)$ & \\
\hline \multicolumn{2}{|c|}{ Hong Kong [28] } & 3.4 & 16.2 & 29 & 5.4 & 149 & 166 & \\
\hline
\end{tabular}

a) Data in bracket is the median value. 
$\mathrm{mg} / \mathrm{kg}$ ) were found within an urban park (Site 5), which might indicate that the park had previously been used in another capacity. Lu et al. [19] also reported that soils in urban parks of this city had the highest mean concentrations of $\mathrm{Cu}, \mathrm{Ni}$, and $\mathrm{Pb}$. Relatively low concentrations of trace metals were often found in areas with a very low density of traffic (e.g., Sites 7 and 16).

In comparison with previous studies conducted in the same city (Table 1), the concentrations of common trace metals in top soils were higher than those reported in 2001 [20], but lower than the values obtained five years ago [19]. In addition, the concentrations of trace metals were notably higher than those in the suburban soil [20] and the background soil from Guangzhou City [21], and in the natural soil from the PRD region [22]. Furthermore, the concentrations of $\mathrm{Co}, \mathrm{Cr}$, and $\mathrm{Ni}$ in this study were very similar to the levels that had been reported in 2001 and five years ago [19, 20]. Trace metal concentrations in urban soils of some Chinese cities published recently (since 2010) are also listed in Table 1. The results in our current study at Guangzhou are comparable with these data. The only exception is that $\mathrm{Pb}$ concentrations in the present Guangzhou study are much lower than those from Hong Kong.

(2) Dust. A similar pattern was seen in the grain size distribution of soil dust and road dust, with fractions of $100-250 \mu \mathrm{m}$ dominating ( $40 \%$ of the total mass) (Figure $2)$. The coarse fractions $(>100 \mu \mathrm{m})$ of road dust were slightly higher than those of soil dust, while the fine fractions $(<100 \mu \mathrm{m})$ were lower than those for soil dust.

It is a common phenomenon that metal concentrations generally increase as grain sizes in soil and dust decrease [9, 27-30]. With regard to soil dust, the concentrations of $\mathrm{Cu}$, $\mathrm{Pb}$, and $\mathrm{Zn}$ increased gradually as grain sizes decreased, while obvious increases in $\mathrm{Cr}$ and $\mathrm{Ni}$ were only found from 100-250 $\mu \mathrm{m}$ to 50-100 $\mu \mathrm{m}$ fractions (Table 2). Cobalt in soil dust was uniformly distributed in these grain fractions. Compared to soil dust, metal concentrations in road dust were much higher, and all of the metals exhibited a trend of dramatic increase as grain sizes decreased (Table 2). Generally, the smallest particles $(<50 \mu \mathrm{m})$ of both soil and road dust had the highest concentrations of trace metals. This may be due to the fact that smaller particles have more

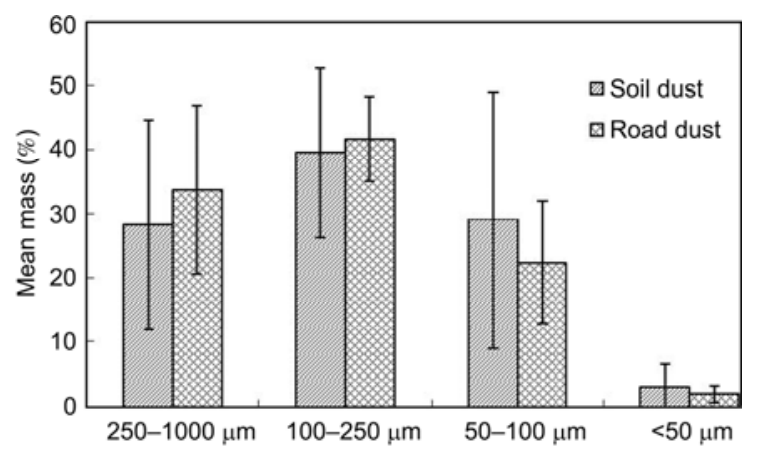

Figure 2 Grain size distribution of road and soil dust. specific surface sites for the adsorption or coating of trace metals [27]. In addition, anthropogenically emitted metalembedded particles are normally in small size fractions. Adachi and Tainosho [31] reported that brake dust contains metal particles, such as $\mathrm{Fe}, \mathrm{Cu}, \mathrm{Zr}, \mathrm{Sb}$, and $\mathrm{Ba}$, with a particle diameter of about $1 \mu \mathrm{m}$. Yellow paint contains $\mathrm{Cr} / \mathrm{Pb}$ particles of about $0.5 \mu \mathrm{m}$. Tire treads have multi-angular $\mathrm{ZnO}$ particles of $1 \mu \mathrm{m}$ or less in diameter [31]. Zhao et al. [30] also found that the smallest particles $(<44 \mu \mathrm{m})$ of road dust from Beijing had the highest metal concentrations. However, the concentrations of $\mathrm{Cr}, \mathrm{Cu}, \mathrm{Pb}$ and $\mathrm{Zn}$ for $<44$ $\mu \mathrm{m}$ grain $(75.5,113,112$ and $591 \mathrm{mg} / \mathrm{kg}$, respectively) in their study were much lower than our results for $<50 \mu \mathrm{m}$ grain.

Since anthropogenic metals tend to be concentrated in fine particles, the concentrations of trace metals in the smallest grain fraction $(<50 \mu \mathrm{m})$ of dust would best reveal the environmental conditions of the location where the sample was collected. High concentrations of trace metals in the $<50 \mu \mathrm{m}$ fraction of road dust were generally found in industrial areas (e.g., Site 14, the GZ steel factory; Site 15, the GZ dockyard), and moderately high concentrations of metals were observed in the sampling locations adjacent to busy roads (e.g., Sites 9 and 10). The lowest metal concentrations were consistently found in the samples collected from side roads (e.g., Sites 16 and 7) where the density of traffic was low.

(3) Tree leaves and grasses. The concentrations of trace metals in the plant samples exhibited narrow ranges, and were found in notably lower levels than those in the soil and dust samples (Table 3). For unwashed tree leaves, the concentrations of $\mathrm{Pb}$ varied most greatly (11 times), from 1.31 to $14.0 \mathrm{mg} / \mathrm{kg}$, followed by $\mathrm{Cr}$ (7 times) from 0.77 to 5.12 $\mathrm{mg} / \mathrm{kg}$. Copper, $\mathrm{Ni}$, and $\mathrm{Zn}$ concentrations varied about two times, from 6.81 to $15.6 \mathrm{mg} / \mathrm{kg}, 0.84$ to $2.09 \mathrm{mg} / \mathrm{kg}$, and 17.4 to $42.9 \mathrm{mg} / \mathrm{kg}$, respectively. When compared with the data in tree leaves of the same species collected at the same sampling sites (Sites 8, 9, and 14) ten years ago (Figure 3) [32], the concentrations of $\mathrm{Pb}$ in the present study had significantly decreased, probably revealing reduced emissions of $\mathrm{Pb}$ in recent years due to the use of lead-free petrol in Guangzhou since 2000. In comparison with metal concentrations from the unwashed leaf samples, about 65\%-99\% of $\mathrm{Cr}, 29 \%-72 \%$ of $\mathrm{Ni}, 18 \%-49 \%$ of $\mathrm{Cu}, 35 \%-76 \%$ of $\mathrm{Pb}$, and $7.5 \%-48 \%$ of $\mathrm{Zn}$ were removed by the washing process, indicating that a substantial amount of the metals in the tree leaves were present as particles adhering to the surface of the leaves rather incorporated in plant tissues. Al-Khashman et al. [10] studied metal retention in date palm leaves from urban areas, and found that metals were removed from leaves through washing at rates of 16\%, 24\%, 28\%, 61\%, and $25 \%$ for $\mathrm{Cr}, \mathrm{Cu}, \mathrm{Ni}, \mathrm{Pb}$, and $\mathrm{Zn}$, respectively. Similarly, the removal of $\mathrm{Cu}, \mathrm{Pb}$, and $\mathrm{Zn}$ from leaves of Robinia pseudoacacia located in an urban-industrial zone were $17 \%-83 \%, 13 \%-56 \%$, and $15 \%-74 \%$, respectively [12]. 
Table 2 Summary of metal concentrations in different particle sizes of soil/road dust

\begin{tabular}{|c|c|c|c|c|c|c|c|}
\hline & & Co & $\mathrm{Cr}$ & $\mathrm{Cu}$ & $\mathrm{Ni}$ & $\mathrm{Pb}$ & $\mathrm{Zn}$ \\
\hline \multicolumn{8}{|l|}{ Soil dust $(n=7)$} \\
\hline \multirow[t]{3}{*}{$250-1000 \mu \mathrm{m}$} & Mean \pm SD & $4.43 \pm 3.51$ & $44.7 \pm 24.4$ & $46.3 \pm 28.6$ & $15.9 \pm 8.13$ & $49.7 \pm 28.2$ & $164 \pm 93.2$ \\
\hline & Median & 2.87 & 40.6 & 42.6 & 13.9 & 36.3 & 143 \\
\hline & Range & $1.24-11.0$ & $16.1-91.1$ & $14.9-89.7$ & $7.08-32.9$ & $22.1-96.7$ & $54.2-328$ \\
\hline \multirow[t]{3}{*}{$100-250 \mu \mathrm{m}$} & Mean \pm SD & $4.78 \pm 2.63$ & $57.1 \pm 26.3$ & $58.4 \pm 32.2$ & $17.3 \pm 6.7$ & $76.1 \pm 36.2$ & $230 \pm 121$ \\
\hline & Median & 3.70 & 54.2 & 46.8 & 15.4 & 75.7 & 217 \\
\hline & Range & $3.13-10.4$ & $27.4-110$ & $29.4-113$ & $11.6-31.6$ & $38.7-135$ & $106-483$ \\
\hline \multirow[t]{3}{*}{$50-100 \mu \mathrm{m}$} & Mean \pm SD & $5.61 \pm 1.80$ & $78.8 \pm 13.4$ & $99.4 \pm 34.1$ & $21.8 \pm 4.4$ & $98.6 \pm 26.1$ & $344 \pm 69$ \\
\hline & Median & 5.66 & 81.7 & 93.4 & 22.2 & 111 & 340 \\
\hline & Range & $3.23-7.77$ & $50.6-91.3$ & $50.4-154$ & $15.2-28.3$ & $52.3-125$ & $210-426$ \\
\hline \multirow[t]{3}{*}{$<50 \mu \mathrm{m}$} & Mean \pm SD & $4.27 \pm 1.85$ & $77.2 \pm 14.4$ & $163 \pm 45.7$ & $22.4 \pm 3.55$ & $114 \pm 33.6$ & $366 \pm 69.8$ \\
\hline & Median & 4.55 & 70.4 & 171 & 22.8 & 115 & 366 \\
\hline & Range & $1.61-6.27$ & $61.3-98.8$ & $103-223$ & $17.4-28.2$ & $69.4-156$ & $273-467$ \\
\hline \multicolumn{8}{|l|}{ Road dust ( $n=22)$} \\
\hline \multirow[t]{3}{*}{$250-1000 \mu \mathrm{m}$} & Mean \pm SD & $2.81 \pm 2.21$ & $36.0 \pm 20.3$ & $68.9 \pm 79.2$ & $9.39 \pm 3.56$ & $40.5 \pm 22.4$ & $196 \pm 139$ \\
\hline & Median & 2.44 & 30.6 & 43.1 & 8.83 & 41.5 & 172 \\
\hline & Range & $\mathrm{nd}^{\text {a) }}-9.25$ & $12.1-94.0$ & $16.7-362$ & $5.12-16.4$ & $11.5-82.5$ & $86.8-765$ \\
\hline \multirow[t]{3}{*}{$100-250 \mu \mathrm{m}$} & Mean \pm SD & $3.89 \pm 2.05$ & $74.2 \pm 29.3$ & $193 \pm 204$ & $21.6 \pm 9.03$ & $104 \pm 86.8$ & $390 \pm 181$ \\
\hline & Median & 3.27 & 72.6 & 114 & 19.3 & 83.4 & 353 \\
\hline & Range & $1.26-9.55$ & $37.4-142$ & $31.7-798$ & $5.94-40.7$ & $29.5-412$ & $108-1040$ \\
\hline \multirow[t]{3}{*}{$50-100 \mu \mathrm{m}$} & Mean \pm SD & $6.31 \pm 2.09$ & $138 \pm 44.3$ & $250 \pm 149$ & $37.2 \pm 14.5$ & $162 \pm 96.8$ & $739 \pm 313$ \\
\hline & Median & 6.06 & 122 & 212 & 34.2 & 141 & 641 \\
\hline & Range & $3.12-10.9$ & $71.1-248$ & $74.9-796$ & $12.8-75.6$ & $77.7-532$ & $257-1560$ \\
\hline \multirow[t]{3}{*}{$<50 \mu \mathrm{m}$} & Mean \pm SD & $8.87 \pm 4.28$ & $176 \pm 63$ & $376 \pm 227$ & $48.3 \pm 16.1$ & $406 \pm 694$ & $1150 \pm 606$ \\
\hline & Median & 9.66 & 174 & 337 & 47.5 & 243 & 1120 \\
\hline & Range & $1.77-16.7$ & $57.7-302$ & $134-1260$ & $16.1-74.5$ & $103-3470$ & $322-3250$ \\
\hline
\end{tabular}

a) nd, non-detectable.

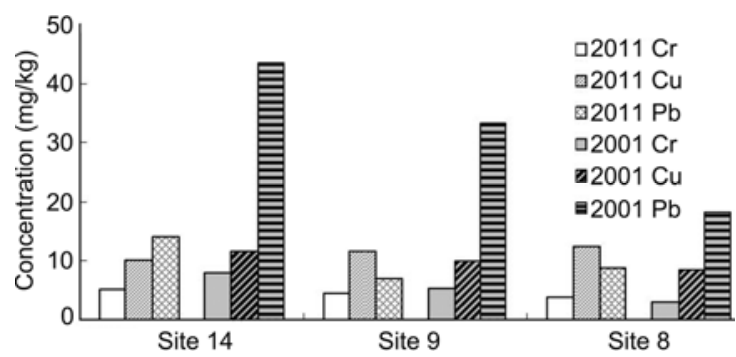

Figure 3 Comparison of $\mathrm{Cr}, \mathrm{Cu}$, and $\mathrm{Pb}$ concentrations of tree leaves between 2011 and 2001 .

Our results were similar $(\mathrm{Cu}, \mathrm{Pb}$, and $\mathrm{Zn})$ or higher $(\mathrm{Cr}$ and $\mathrm{Ni}$ ) than the levels observed from these two plants, which had been considered by the authors to be suitable indicators of air pollution. This shows that the plant Ficus microcarpa would be an ideal bioindicator of airborne metal pollution in the urban areas of this region.

In comparison with tree leaves, the variations in metal concentrations of the grass samples were smaller, from two $(\mathrm{Cu})$ to five times $(\mathrm{Pb})$. However, the concentrations of $\mathrm{Cr}$,
$\mathrm{Ni}$, and $\mathrm{Zn}$ in the grass samples were significantly higher $(P<0.05)$ than those in the tree leaves. The differences in metal concentrations between unwashed and washed grasses were not as significant as those for the tree leaves. Washing can remove only $19 \%$ of $\mathrm{Pb}$, and $7.2 \%$ of $\mathrm{Zn}$, and no significant amounts of $\mathrm{Cr}, \mathrm{Cu}$, and $\mathrm{Ni}$ from the grasses.

The spatial distribution patterns of trace metals in the tree leaves were similar to those of the road dust. High concentrations of metals were found in the industrial area (Site 14, the GZ steel factor), and low concentrations were observed in the urban park away from the main roads (Site 4). However, these distribution patterns for grass samples were not as notable as those for the tree leaves.

\subsection{Relationships between metal concentrations}

The results of the correlation analysis of metal concentrations for soil, soil dust and road dust, and tree leaf and grass samples are presented in Tables 4-6, respectively. Strong correlations between metals were found in surface soils, while the correlations were less significant for top soils 
Table 3 Summary of metal concentrations of tree leaves and grasses ${ }^{\text {a) }}$

\begin{tabular}{|c|c|c|c|c|c|c|}
\hline & & $\mathrm{Cr}$ & $\mathrm{Cu}$ & $\mathrm{Ni}$ & $\mathrm{Pb}$ & $\mathrm{Zn}$ \\
\hline \multicolumn{7}{|l|}{ Tree leaves $(n=21)$} \\
\hline \multirow[t]{3}{*}{ Unwashed } & Mean \pm SD & $2.99 \pm 1.05$ & $11.0 \pm 2.5$ & $1.50 \pm 0.36$ & $6.72 \pm 3.47$ & $28.7 \pm 8.1$ \\
\hline & Median & 2.97 & 10.8 & 1.52 & 5.52 & 28.2 \\
\hline & Range & $0.77-5.18$ & $6.81-15.6$ & $0.84-2.09$ & $1.31-14.0$ & $17.4-42.9$ \\
\hline \multirow[t]{2}{*}{ Washed } & Mean \pm SD & $0.38 \pm 0.40$ & $6.96 \pm 1.20$ & $0.67 \pm 0.22$ & $2.96 \pm 1.79$ & $20.0 \pm 4.17$ \\
\hline & Range & $\mathrm{nd}^{\mathrm{b})}-1.51$ & $4.64-9.32$ & $0.41-1.29$ & $0.59-7.78$ & $13.3-28.9$ \\
\hline \multicolumn{7}{|l|}{ Grasses $(n=20)$} \\
\hline \multirow[t]{3}{*}{ Unwashed } & Mean \pm SD & $26.4 \pm 11.8$ & $12.1 \pm 2.3$ & $12.0 \pm 5.5$ & $5.47 \pm 2.75$ & $50.7 \pm 10.0$ \\
\hline & Median & 23.0 & 11.6 & 10.4 & 4.34 & 52.2 \\
\hline & Range & $14.8-59.6$ & $6.97-17.0$ & $7.06-268$ & $2.84-13.3$ & $26.8-70.3$ \\
\hline \multirow{2}{*}{ Washed } & Median & 21.4 & 12.5 & 10.5 & 3.31 & 48.0 \\
\hline & Range & $11.0-34.3$ & $7.82-15.8$ & $6.89-19.6$ & $2.08-10.2$ & $29.3-60.3$ \\
\hline
\end{tabular}

a) Cobalt concentrations are not listed because many of them were below the detection limit; b) nd, non-detectable.

(Table 4). For soil dust, significant correlations of metals were mainly found in coarse fractions $(>100 \mu \mathrm{m})$. For road dust, such relationships were generally observed in fine fractions $(<100 \mu \mathrm{m})$ (Table 5). The results indicated that trace metals in finer particles of road dust had more likely been influenced by the same sources (e.g., vehicle related emissions), while for metals in coarser fractions, the sources may have been more diverse; and vice versa for soil dust. For plant samples, the correlations of metals in tree leaves were more significant than those in grass samples (Table 6). The diverse relationships among trace metals may reveal the different loadings of metal pollutants into distinguished environmental compartments (receptors) in urban environments.

\subsection{Relationships of metals between sample types}

(1) Correlation between tree leaves and road dust. A correlation analysis showed that concentrations of $\mathrm{Pb}$ in the smallest particles of dust $(<50 \mu \mathrm{m})$ were significantly correlated to the $\mathrm{Pb}$ in tree leaves (Figure 4), suggesting that local traffic emissions were the main source of the $\mathrm{Pb}$ that had accumulated on the tree leaves, since metals concentrated in road dust are mainly derived from trafficassociated particles [33]. The three sampling sites close to industrial facilities, including the GZ dockyard (Site 15), the GZ cotton mill (Site 21), and a hardware market (Site 22), all had high concentrations of $\mathrm{Pb}$ in road dust, and relatively low concentrations of $\mathrm{Pb}$ in tree leaves, and thus were away from the linear trend of the majority of the samples (Figure 4). This result reflected the different responses between road dust and tree leaves to the $\mathrm{Pb}$ emitted from these industrial facilities.

With the exception of $\mathrm{Pb}$, significant correlations between road dust and tree leaves were not found for other metals, which suggest that these metals in tree leaves came not only from local road-traffic sources, but also from non-traffic pollutants in the wider urban area. It was

Table 4 Pearson correlation coefficients ( $r$ ) of trace metals in surface soils and top soils

\begin{tabular}{|c|c|c|c|c|c|}
\hline & Co & $\mathrm{Cr}$ & $\mathrm{Cu}$ & $\mathrm{Ni}$ & $\mathrm{Pb}$ \\
\hline \multicolumn{6}{|c|}{ Surface soils $(n=22)$} \\
\hline $\mathrm{Cr}$ & 0.319 & & & & \\
\hline $\mathrm{Cu}$ & 0.353 & $0.501 *$ & & & \\
\hline $\mathrm{Ni}$ & $0.744 * *$ & 0.307 & $0.708^{* *}$ & & \\
\hline $\mathrm{Pb}$ & 0.046 & $0.476^{*}$ & $0.721 * *$ & 0.186 & \\
\hline $\mathrm{Zn}$ & 0.178 & $0.922 * *$ & $0.671 * *$ & 0.268 & $0.715 * *$ \\
\hline $\mathrm{Cr}$ & 0.326 & & & & \\
\hline $\mathrm{Cu}$ & 0.073 & $0.549 * *$ & & & \\
\hline $\mathrm{Ni}$ & $0.465^{*}$ & 0.371 & $0.600 * *$ & & \\
\hline $\mathrm{Pb}$ & 0.036 & 0.398 & $0.785^{* *}$ & 0.229 & \\
\hline $\mathrm{Zn}$ & 0.063 & $0.774 * *$ & $0.647 * *$ & 0.185 & $0.609 * *$ \\
\hline
\end{tabular}

${ }^{*} P<0.05, * * P<0.01$ (two-tailed). 
Table 5 Pearson correlation coefficients $(r)$ of trace metals in soil dust and road dust

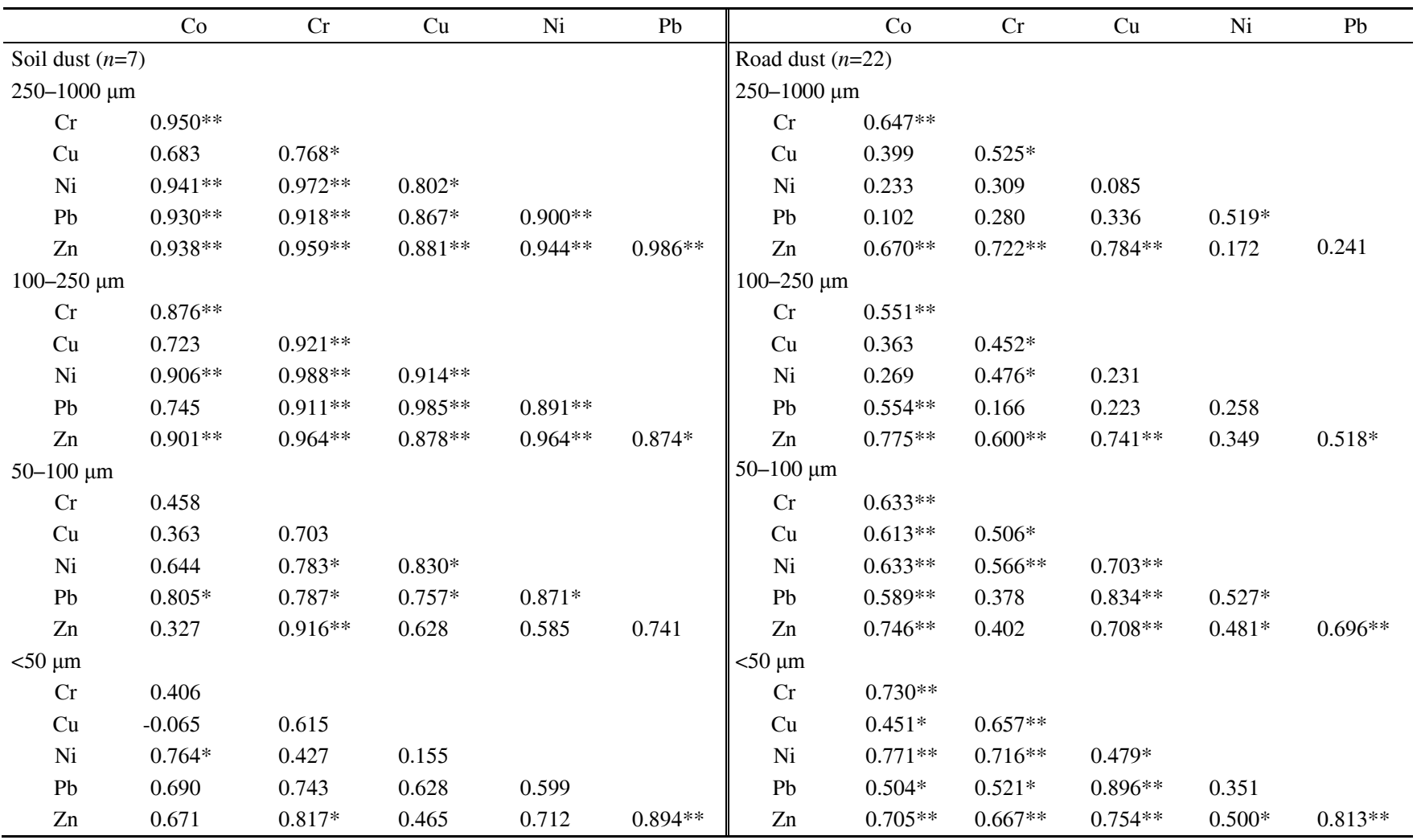

$* P<0.05, * * P<0.01$ (two-tailed).

Table 6 Pearson correlation coefficients $(r)$ of trace metals in unwashed tree leaves and grasses

\begin{tabular}{cclcc}
\hline & $\mathrm{Cr}$ & $\mathrm{Cu}$ & $\mathrm{Ni}$ & $\mathrm{Pb}$ \\
\hline Tree leaves $(n=21)$ & & & & \\
$\mathrm{Cu}$ & $0.539^{*}$ & & & \\
$\mathrm{Ni}$ & $0.727^{* *}$ & $0.634^{* *}$ & & \\
$\mathrm{~Pb}$ & $0.737^{* *}$ & $0.468^{*}$ & $0.480^{*}$ & \\
$\mathrm{Zn}$ & $0.712^{* *}$ & $0.658^{* *}$ & $0.657^{* *}$ & $0.644^{* *}$ \\
Grasses $(n=20)$ & & & & \\
$\mathrm{Cu}$ & 0.413 & & & \\
$\mathrm{Ni}$ & $0.991^{* *}$ & 0.440 & & \\
$\mathrm{~Pb}$ & -0.042 & 0.112 & -0.132 & \\
$\mathrm{Zn}$ & $0.526^{*}$ & $0.504 *$ & $0.525 *$ & 0.109 \\
\hline
\end{tabular}

$* P<0.05, * * P<0.01$ (two-tailed).

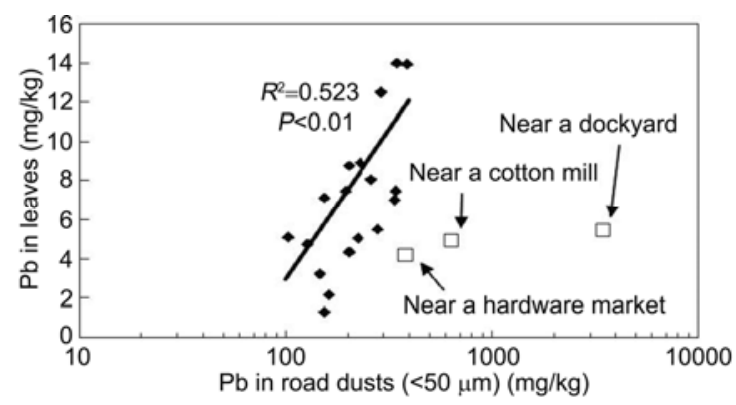

Figure 4 Correlation of $\mathrm{Pb}$ concentrations between road dusts $(<50 \mu \mathrm{m})$ and tree leaves. reported that the majority of particles observed on tree leaves belonged to a class of fine particles $(<2 \mu \mathrm{m})$ [34]. The fine particles, such as $\mathrm{PM}_{10}$, from the roadside had come from both urban sources and local traffic emissions [33].

(2) Correlation between soils and soil dust. There were no significant correlations of metal concentrations between soils (both surface soils and top soils) and overall soil dust (the sum of the metal concentrations in each fraction multiplied by its mass percentage). However, the $\mathrm{Co}$ and $\mathrm{Ni}$ in the fraction of 50-100 $\mu \mathrm{m}$ of soil dust were significantly correlated to those in surface soils (Figure 5), which suggests that the $\mathrm{Co}$ and $\mathrm{Ni}$ in the soil dust $(50-100 \mu \mathrm{m})$ were mainly derived from soil materials. The concentrations of these two metals in both soils and soil dust were similar to the background values, reflecting their geogenic origin. The absence of correlations for other metals indicated that these metals $(\mathrm{Cr}, \mathrm{Cu}, \mathrm{Pb}$, and $\mathrm{Zn})$ in soil dust had not originated predominantly from the soils. Soil dust is situated at the air-soil interface so it acts as a link between the atmosphere and soil. The present study confirmed that metals in the soil dust were partially derived from soils and partially from atmospheric deposition (e.g., local traffic and urban-wide deposition). Furthermore, the relationships of trace metals between soil dust and surface soils indicated that surface soils $(0-3 \mathrm{~cm})$ could reflect the conditions of both atmospheric deposition and soil materials. However, soils in the top $15 \mathrm{~cm}$ may not effectively reveal airborne trace metal 


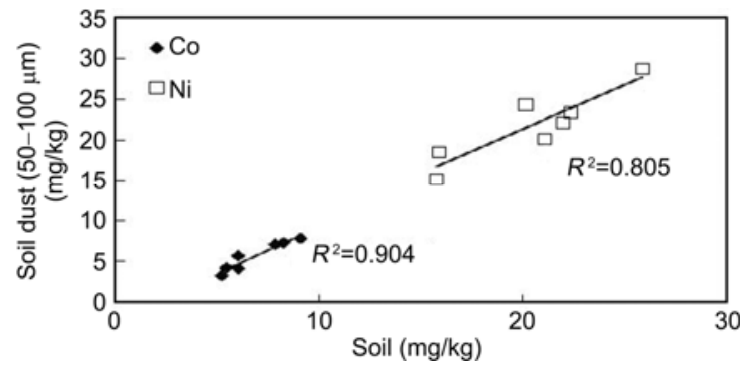

Figure 5 Correlations of $\mathrm{Co}$ and $\mathrm{Cr}$ concentrations between surface soils and soil dust $(50-100 \mu \mathrm{m})$.

pollution. It is well known that trace metals are present in soils in different chemical forms, and vary widely in solubility or bioavailability [2]. Generally, metals derived from anthropogenic sources have a relatively higher degree of bioavailability than those from natural sources (soil materials) $[2,35]$. Therefore, the difference in metal origins among soil dust, surface soils, and top soils can induce different outputs in terms of risk assessment, despite the fact that they have similar total metal concentrations.

\section{Conclusions}

An integrative investigation of trace metal $(\mathrm{Co}, \mathrm{Cr}, \mathrm{Cu}, \mathrm{Ni}$, $\mathrm{Pb}$, and $\mathrm{Zn}$ ) contamination in different sample matrices, including soils, dusts, and plants, were conducted in a typical urban area of Guangzhou City. The concentrations of trace metals varied greatly among different sample types. Surface soils had metal concentrations similar to those of top soils. In the case of road and soil dust, trace metals had a tendency to concentrate in fine particles $(<100 \mu \mathrm{m})$. There were significant differences in metal concentrations between unwashed and washed tree leaves, while the differences between unwashed and washed grass samples were not significant. The overall trend in the distribution of metals among different samples was generally as follows: road dust $>$ soil dust $\geqslant$ surface soils $\approx$ top soils $>$ grasses $\geqslant$ tree leaves. The spatial distribution patterns of trace metals indicated that industrial activities and traffic emissions were the major sources of metal contaminants in the urban environment of Guangzhou. The trace metals exhibited different combination features among different samples, indicating different loadings of trace metals among sampling types. Significant correlations of metal concentrations were found between tree leaves and the smallest $(<50 \mu \mathrm{m})$ fraction of road dust, and between soil dust $(50-100 \mu \mathrm{m})$ and surface soils, suggesting that the trace metals in these samples may influence each other. Our results in the present study provided useful information about interrelationships in integrated environmental compartments in urban areas.

This work was supported by the Sustainable Urbanization Research Fund (SURF) from the Faculty of Construction and Environment at The Hong
Kong Polytechnic University (1-ZV4M), and the National Natural Science Foundation of China (40903041).

1 Ajmone-Marsan F, Biasioli M. Trace elements in soils of urban areas. Water Air Soil Pollut, 2010, 213: 121-143

2 Luo X S, Yu S, Zhu Y G, et al. Trace metal contamination in urban soils of China. Sci Total Environ, 2012, 421-422: 17-30

3 Laidlaw M A S, Mielke H W, Filippelli G M, et al. Seasonality and children's blood lead levels: Developing a predictive model using climatic variables and blood lead data from Indianapolis, Indiana, Syracuse, New York, and New Orleans, Louisiana (USA). Environ Health Perspect, 2005, 113: 793-800

4 Ren H, Wang J, Zhang X. Assessment of soil lead exposure in children in Shenyang, China. Environ Pollut, 2006, 144: 327-335

5 Laidlaw M A S, Taylor M P. Potential for childhood lead poisoning in the inner cities of Australia due to exposure to lead in soil dust. Environ Pollut, 2011, 159: 1-9

6 Amato F, Querol X, Johansson C, et al. A review on the effectiveness of street sweeping, washing and dust suppressants as urban PM control methods. Sci Total Environ, 2010, 408: 3070-3084

7 Mossetti S, Angius S, Angelino E. Assessing the impact of particulate matter sources in the Milan urban area. Intl J Environ Pollut, 2005, 24: 247-259

8 Han S, Youn J S, Jung Y W. Characterization of PM10 and PM2.5 source profiles for resuspended road collected using mobile sampling methodology. Atmos Environ, 2011, 45: 3343-3351

9 Madrid F, Biasioli M, Ajmone-Marsan F. Availability and bioaccessibility of metals in fine particles of some urban soils. Arch Environ Contam Toxicol, 2008, 55: 21-32

10 Al-Khashman O A, Al-Muhtaseb A H, Ibrahim K A. Date palm (Phoenix dactylifera L.) leaves as biomonitors of atmospheric metal pollution in arid and semi-arid environments. Environ Pollut, 2011, 159: $1635-1640$

11 Sawidis T, Breuste J, Mitrovic M, et al. Trees as bio-indicator of heavy metal pollution in three European cities. Environ Pollut, 2011, 159: 3560-3570

12 Serbula S M, Miljkovic D D, Kovacevic R M, et al. Assessment of airborne heavy metal pollution using plant parts and topsoil. Ecotox Environ Safe, 2012, 76: 209-214

13 Duzgoren-Aydin N. Sources and characteristics of lead pollution in the urban environment of Guangzhou. Sci Total Environ, 2007, 385: 182-195

14 Guangzhou Yearbook. Guangzhou: Guangzhou Year-book Press, 2010

15 Luo X S, Yu S, Li X D. The mobility, bioavailability, and human bioaccessibility of trace metals in urban soils of Hong Kong. Appl Geochem, 2012, 27: 995-1004

16 Li X D, Lee S L, Wong S C, et al. The study of metal contamination in urban soils of Hong Kong using a GIS-based approach. Environ Pollut, 2004, 129: 113-124

17 Luo C L, Liu C P, Wang Y, et al. Heavy metal contamination in soils and vegetables near an e-waste processing site, south China. J Hazard Mater, 2011, 186: 481-490

18 Huang D Y, Xu Y G, Peng P A, et al. Chemical composition and seasonal variation of acid deposition in Guangzhou, south China: Comparison with precipitation in other major Chinese cities. Environ Pollut, 2009, 157: 35-41

$19 \mathrm{Lu} \mathrm{Y,} \mathrm{Zhu} \mathrm{F,} \mathrm{Chen} \mathrm{J,} \mathrm{et} \mathrm{al.} \mathrm{Chemical} \mathrm{fractionation} \mathrm{of} \mathrm{heavy} \mathrm{metals} \mathrm{in}$ urban soils of Guangzhou, China. Environ Monit Assess, 2007, 134: 429-439

20 Guan D S, Chen Y J, Yuan G B. Study on heavy metal concentrations and the impact of human activity on them in urban and suburb soils of Guangzhou. Acta Scientiarum Maturalium University Sunyatseni, 2001, 40: 93-96

21 Guangdong Geological Survey (GGS). Multi-purposes geochemical survey: Pear River Delta, Guangdong Province, 2010

22 Wong S C, Li X D, Zhang G, et al. Heavy metals in agricultural soils of the Pear River Delta. Environ Pollut, 2002, 119: 33-44 
23 Xia X, Chen X, Liu R, et al. Heavy metals in urban soils with various types of land use in Beijing, China. J Hazard Mater, 2011, 186: 2043-2050

24 Sun Y, Zhou Q, Xie X, et al. Spatial, sources and risk assessment of heavy metal contamination of urban soils in typical regions of Shenyang, China. J Hazard Mater, 2010, 174: 455-462

25 Luo X S, Ding J, Xu B, et al. Incorporating bioaccessibility into human health risk assessments of heavy metals in urban park soils. Sci Total Environ, 2012, 424: 88-96

26 Guo G, Wu F, Xie F, et al. Spatial distribution and pollution assessment of heavy metals in urban soils from southwest China. J Environ Sci, 2012, 24: 410-418

27 Duong T T T, Lee B K. Determining contamination level of heavy metals in road dust from busy traffic areas with different characteristic. J Environ Manag, 2011, 92: 554-562

28 Luo X S, Yu S, Li X D. Distribution, availability, and sources of trace metals in different particle size fractions of urban soils in Hong Kong: Implications for assessing the risk to human health. Environ Pollut, 2011, 159: 1317-1326

29 Zhao H, Li X, Wang X. Heavy metal contents of road-deposited sediment along the urban-rural gradient around Beijing and its potential contribution to runoff pollution. Environ Sci Technol, 2011, 45: 7120-7127

30 Zhao H, Li X, Wang X, et al. Grain size distribution of roaddeposited sediment and its contribution to heavy metal pollution in urban runoff in Beijing, China. J Hazard Mater, 2010, 183: 203-210

31 Adachi K, Tainosho Y. Characterization of heavy metal particles embedded in tire dust. Environ Int, 2004, 30: 1009-1017

32 Ma Y L, Jia G M, Wang Y P, et al. Contents of heavy metal in leaves of plants and air pollution evaluation in Guangzhou region. Urban Environ Urban Ecol, 2001, 14: 28-30

33 Lin H Y, Hung C H, Yuan C S, et al. Characteristics and source identification of roadside suspended particles. Transport Res, 2008, 13: 531-538

34 Tomašević M, Vukmirović Z, Rajšić S, et al. Characterization of trace metal particles deposited on some deciduous tree leaves in an urban area. Chemosphere, 2005, 61: 753-760

35 Lamb D T, Ming H, Megharaj M, et al. Heavy metal (Cu, Zn, Cd and $\mathrm{Pb}$ ) partitioning and bioaccessibility in uncontaminated and longterm contaminated soils. J Hazard Mater, 2009, 171: 1150-1158

Open Access This article is distributed under the terms of the Creative Commons Attribution License which permits any use, distribution, and reproduction in any medium, provided the original author(s) and source are credited. 